\title{
Improvement in yield and fruit size and quality of the main Italian table olive cultivar 'Nocellara del Belice'
}

\author{
Ettore Barone, Michele La Mantia, Annalisa Marchese, Francesco Paolo Marra*
}

University of Palermo - Dept. of Agricultural and Forest

Sciences, Viale delle Scienze Edificio 4 Ingresso H - 90128

- Palermo - Italy.

*Corresponding author <francescopaolo.marra@unipa.it>

Edited by: Lincoln Zotarelli

Received June 13, 2013

Accepted September 05, 2013

\begin{abstract}
Olive (Olea europaea L.) shows alternate bearing, with unreliable cropping patterns and inconsistent fruit size and quality every year. In many countries, thinning with naphthaleneacetic acid (NAA) is used to minimise alternate bearing behavior in olives. However, in Italy, growers are reluctant to employ this practice and no detailed knowledge is available for specific cultivars. We evaluated the effects of spraying NAA on various dates on the productive and vegetative characteristics of the main Italian table olive cultivar 'Nocellara del Belice'. Trunk cross-sectional area, fruit set, fruit drop, fruit size, pit size, yield per tree, crop density and flesh to pit ratio were analysed. The NAA treatment applied on the earliest of the dates selected increased fruit weight and flesh to pit ratio, by reducing crop density and enhancing the leaf to fruit ratio, without reducing yield. Two distinct negative relationships were found between fruit weight and crop density during "on" and "off" years, but a unique relationship between pit weight vs. crop density in both years, suggested that the pit is the strongest sink. Fruit size and quality of 'Nocellara del Belice' can be enhanced by NAA application, thereby increasing economic returns in the "on" year.
\end{abstract}

\section{Introduction}

In many fruit species, part of the crop is removed in the early stages of fruit development to improve the quality of the remaining crop, mainly in terms of fruit size. In table olive (Olea europaea L.), heavy crop loads result in small fruit of lesser value, late maturity, poor quality ultimately leading to depressed prices (Martin et al., 1980). Moreover, excessive crop loads and excessive numbers of developing seeds decrease or inhibit flowerbud formation which can contribute to the biennial production pattern (Dag et al., 2010; Fernandez-Escobar et al., 1992; Lavee, 1989, 2007; Stutte and Martin, 1986).

In Sicily, which is home to more than $47 \%$ of the entire Italian olive production under rain-fed conditions, growers adopt severe pruning practices to reach a balance between vegetative growth, fruit production and quality. In semi-arid environments, pruning can affect soil water availability and consequently it is used for the purpose of reducing the crop and increasing fruit size (Rallo and Barranco, 1986). However, other techniques can be adopted, such as thinning, which do not alter the root/shoot ratio (Hartmann, 1952). Chemical thinning with products that reduce crop load by reducing bloom (Baratta et al., 1992; Lavee and Spiegel-Roy, 1967) or enhancing fruitlet abscission are applied not only to improve fruit size, but also to moderate alternate bearing (Hartmann, 1952; Krueger et al., 2002).

Naphthaleneacetic acid (NAA) is an exogenous hormone used as a thinning agent in many fruit species. It is thought that NAA may influence the rate of metabolic activity of developing embryos and it also stimulates the ethylene biosynthesis, which inhibits fruit growth and promotes the abscission of weaker fruits (Williams and Fallahi, 1999). NAA in post-bloom applications effective- ly improves fruit quality for several table olive cultivars and has been widely used in the Californian and Israeli olive industry for many years (Dag et al., 2009; Maranto and Krueger, 1994) but it is not common cultural practice in Italy or other Mediterranean countries.

The main Italian table olive cultivar - 'Nocellara del Belice' - is characterised by an average fruit weight of $7.4 \mathrm{~g}$ (Marra et al., 2013) and a production of 5 ton $\mathrm{ha}^{-1}$ in the "on" year. The fluctuation of production between the "on" year and the "off" year is estimated at $1.5 \mathrm{t} \mathrm{ha}^{-1}$ which critically compromises market and economic returns. Previous studies have shown the thinning effect of using NAA at $200 \mathrm{mg} \mathrm{L}^{-1}$ when applied ten days after full bloom, confirming that the effectiveness of thinning with NAA may vary depending upon cultivar, concentration, timing and environmental factors (Martin et al., 1994; Wertheim and Webster, 2005). We report successive refinements of previous research conducted in Sicily focusing on 'Nocellara del Belice' to determine the optimal timing of NAA application to improve fruit size and quality and possibly to control alternate bearing.

\section{Materials and Methods}

Trials were carried out in Sicily in 2008 and 2009 in a commercial 'Nocellara del Belice' table olive orchard established in 1976, located in the Belice valley (Castelvetrano, $37^{\circ} 40^{\prime} \mathrm{N}, 12^{\circ} 52^{\prime} \mathrm{E}, 50 \mathrm{~m}$ a.s.l.). The soil is a typic Rhodoxeralfs with medium-low $\mathrm{N}, \mathrm{K}$ and organic matter and adequate $\mathrm{P}$ content. The climate of the Belice valley is Mediterranean, semi-arid, with an average rainfall of $538 \mathrm{~mm}$ per year, mainly distributed in autumn and winter $(46 \%$ and $32 \%$, respectively); the remaining in spring and in summer accounts for $14 \%$ and $8 \%$ of the total, respectively. 
Trees are trained to the traditional vase "umbrella shape", planted at distances of $7.5 \times 7.5 \mathrm{~m}$ and they are regularly sprinkle irrigated over about 1,500 $\mathrm{m}^{3} \mathrm{ha}^{-1}$. Trees of 'Biancolilla' and 'Giarraffa' cultivars are interspersed as pollinators. In 2008, a total of 25 trees were selected based on homogeneity of canopy dimension and flower load in five randomized blocks. Experiments were conducted using NAA at a concentration of 200 $\mathrm{mg} \mathrm{L} \mathrm{L}^{-1}$, applied by foliar spray to the point of runoff. In 2008, the treatments were performed 8, 12, 16 and 20 days after full bloom (DAFB). Since treatments at 16 and 20 DAFB were ineffective, in the second year, earlier treatments were chosen and applied to a total of 20 trees as follows: at 6 DAFB (on new trees untreated the previous year), 8 and 12 DAFB (on the same trees treated in 2008).

Fifteen days before FB, four homogeneous oneyear old branchlets per tree were tagged at each cardinal point of the crown. FB dates were recorded as May 18 and May 20, in 2008 and 2009, respectively. At full bloom, trunk cross-sectional area (TCSA), at 15 $\mathrm{cm}$ above graft union, the number of inflorescences per shoot and finally, the number of flowers per inflorescence were all evaluated. Weekly, during the first 60 days after FB, fruit set and fruit drop were monitored, whereas fruit growth was measured biweekly from 60 to 150 days after FB using a sample of 30 fruits from not labelled branchlets.

At harvest time, yield per tree, size and fresh weight of fruit and pit were also determined. Some indicators such as crop density i.e. fruit number TCSA ${ }^{-1}$ (Lombard et al., 1988) and flesh to pit ratio were then calculated. All statistical analyses were performed using Systat statistical packages (SYSTAT, Inc., Evanston, IL).

\section{Results and Discussion}

Most of the fruit abscission occurred during the first 3-4 weeks after bloom (Figure 1A). The application of NAA 8-12 days after full bloom increased $(p<0.05)$ fruit drop when compared to the untreated control trees. In the second year (2009) the overall fruit drop was greater (above $99 \%$; Figure 1B). At the end of the second year only slight differences were observed, indicating a more pronounced effect from the application of NAA eight days after full bloom (99.7 \%) (Figure 1B). Furthermore, on comparing both years, a different pattern of fruit drop emerged (Figure 1A, B). In 2008, fruit drop, measured 12 DAFB, reached almost $90 \%$ for all treatments, whereas in 2009 at the same date, it ranged between $55 \%$ to $75 \%$. Moreover, the fruit drop recorded in control trees was significantly higher in 2009 (99 \%) than 2008 (97 $\%)$ denoting a strong year effect on this parameter, as a consequence of the crop load of the previous year rather than an effect of the treatment by itself.

A remarkable effect of alternate bearing was observed between the two years of the trial, with an average yield of $21.6 \mathrm{~kg}$ per tree in 2008, the "on" year, versus $8.25 \mathrm{~kg}$ per tree in 2009, the "off" year, which represents $38 \%$ of the previous year's production (Table 1). These data are comparable with those generally obtained in Sicily, in the growing area of 'Nocellara del Belice' (Baratta et al., 1992).

Seasonal development of fruit weight is reported in Figure 2. Consistent with the differences observed in fruit drop, the reduction of fruitlets resulted in increased $(p<$ 0.05 ) fruit weight for trees with the earliest application of NAA (Table 1). Proietti et al. (2006) evaluated the effect of leaf-to-fruit ratios on fruit growth in olive. They reported

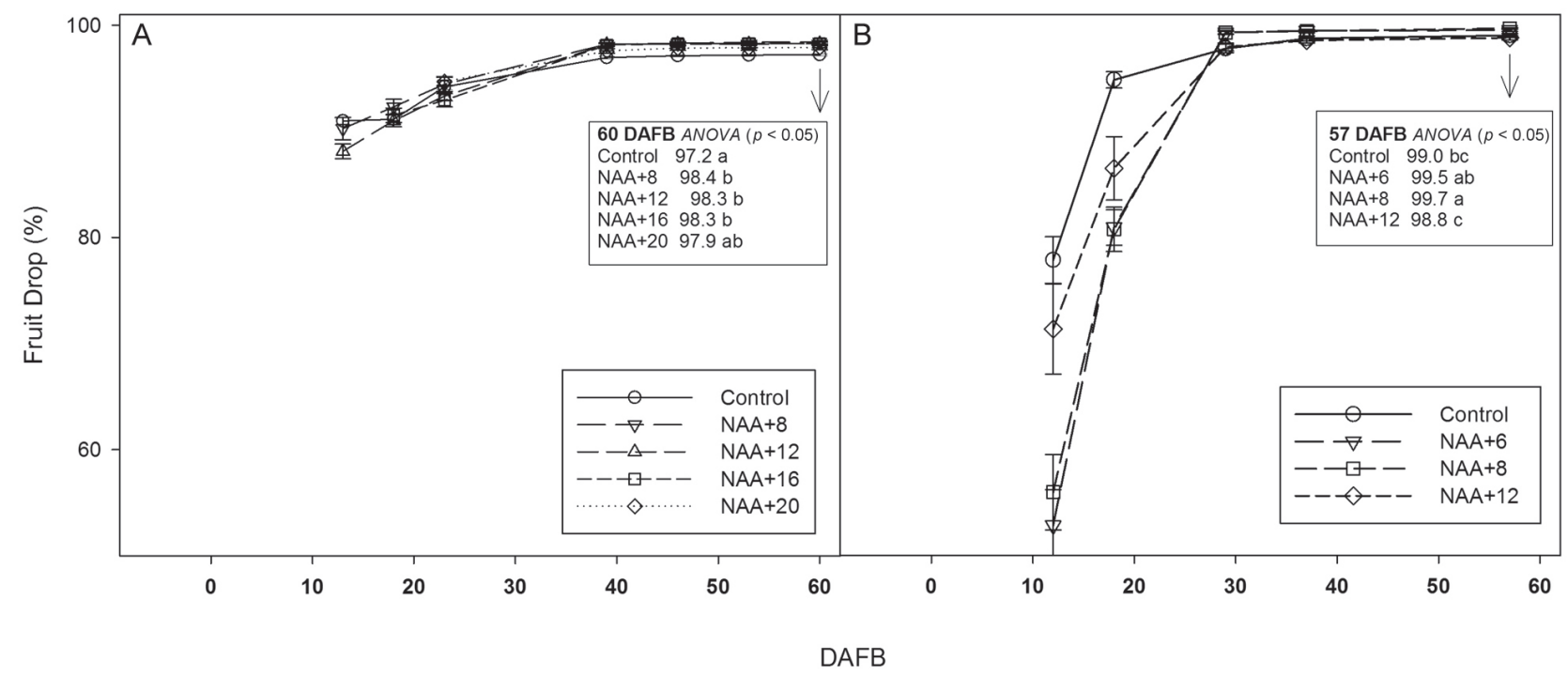

Figure 1 - Fruit drop percentage of table olive 'Nocellara del Belice' trees, after chemical thinning with naphthaleneacetic acid (NAA) (200 mg L-1) at $6,8,12,16$ and 20 days after full bloom (DAFB). Mean values \pm S.E.M. Values with the same letter are not different (Tukey test, $p<0.05)$. A: 2008; B: 2009. 
that all fruit growth phases were affected by the availability of assimilates, but the greatest effect of leaf area available to the fruits was observed at the beginning of fruit growth. This finding is consistent with our results and it is confirmed by the inverse relationship observed between fruit weight and crop density (Figure 3), which is indirectly an indicator of the leaf-to-fruit ratio (Lombard et al., 1988). Thus, a higher crop density resulted in a lower average fruit and pit weight (Table 1; Figure 3A, B).

There was a year effect on crop density and fruit weight (Figure 3A). The difference in the slope between 2008 and 2009 probably denotes the effect of the previous year's fruit load on fruit weight. Conversely, the relationship between crop density and pit weight was fitted by a single model when the data were pooled across the years (Figure 3B). In olive, alternate bearing has a strong effect on fruit weight (Hartmann, 1952; Lavee and Spiegel-Roy, 1967; Troncoso et al., 1978). Fruit number and size are often negatively correlated (Barone et al., 1994; Gucci et al., 2007; Lavee and Wodner, 1991). This relationship is mostly accounted for by changes in the mesocarp fresh weight, while the pit weight is only moderately affected by the fruit load (Lavee and Wodner, 2004).

Two different negative relationships, between olive fruit weight and crop density during "on" and "off" years were found (Figure 3A). When comparing the same level of crop density, olive trees produced larger fruits during a year of heavy crop load (2008), denoting an effect of the previous year's crop status on whole fruit size. The pit weight was only affected by the current year's fruit load, as indicated by the negative relationship between crop density and the endocarp weight (Figure 3B).

In 2009 larger fruit size was expected as a consequence of the reduced crop, while the average fruit weight was comparable in both years and only the pit fresh weight was heavier; this increase in pit weight was associated with a lower flesh to pit ratio (Table 1). This indicates that the endocarp growth represents a stron-

Table 1 - Vegetative and productive characteristics of table olive 'Nocellara del Belice' trees, subjected to chemical thinning with naphthaleneacetic acid (NAA) (200 $\mathrm{mg} \mathrm{L}^{-1}$ ) at 6, 8, 12, 16 and 20 days after full bloom (DAFB).

\begin{tabular}{|c|c|c|c|c|c|c|c|c|c|c|c|c|}
\hline \multirow{3}{*}{ Treatment } & \multirow{2}{*}{\multicolumn{2}{|c|}{$\begin{array}{c}\text { Trunk cross-sectional } \\
\text { area (TCSA) } \\
\left(\mathrm{cm}^{2}\right)\end{array}$}} & \multirow{2}{*}{\multicolumn{2}{|c|}{$\begin{array}{c}\text { Yield/Tree } \\
(\mathrm{kg})\end{array}$}} & \multirow{2}{*}{\multicolumn{2}{|c|}{$\begin{array}{c}\text { Crop Density } \\
\text { (Fruit no. } \mathrm{cm}^{-2} \text { TCSA) }\end{array}$}} & \multirow{2}{*}{\multicolumn{2}{|c|}{$\begin{array}{c}\text { Fruit Weight } \\
\text { (g) }\end{array}$}} & \multirow{2}{*}{\multicolumn{2}{|c|}{$\begin{array}{c}\text { Pit Weight } \\
\text { (g) }\end{array}$}} & \multirow{2}{*}{\multicolumn{2}{|c|}{ Flesh/Pit }} \\
\hline & & & & & & & & & & & & \\
\hline & 2008 & 2009 & 2008 & 2009 & 2008 & 2009 & 2008 & 2009 & 2008 & 2009 & 2008 & 2009 \\
\hline Control & 293 NS & 303 NS & 23 NS & $9 \mathrm{NS}$ & $10.1 \mathrm{a}$ & $4.1 \mathrm{a}$ & $6.9 \mathrm{~d}$ & $7.1 \mathrm{~b}$ & $0.78 \mathrm{~b}$ & $1.01 \mathrm{NS}$ & $7.8 \mathrm{~b}$ & $6.1 \mathrm{NS}$ \\
\hline $\mathrm{NAA}+6$ & - & 449 & - & 6 & - & $1.7 \mathrm{~b}$ & - & $8.4 \mathrm{a}$ & - & 1.10 & - & 6.6 \\
\hline $\mathrm{NAA}+8$ & 304 & 344 & 16 & 7 & $5.9 b$ & $2.3 a b$ & $9.0 \mathrm{a}$ & $8.3 \mathrm{a}$ & 0.93 a & 1.14 & $8.7 \mathrm{a}$ & 6.3 \\
\hline $\mathrm{NAA}+16$ & 309 & - & 21 & - & $9.2 a b$ & - & $7.5 \mathrm{c}$ & - & $0.77 \mathrm{~b}$ & - & 8.7 a & - \\
\hline $\mathrm{NAA}+20$ & 271 & - & 24 & - & $11.8 \mathrm{a}$ & - & $7.5 \mathrm{c}$ & - & $0.83 \mathrm{ab}$ & - & $8.1 \mathrm{ab}$ & - \\
\hline
\end{tabular}

Values with the same letter within the same column are not different (Tukey test, $p<0.05$; NS = non-significant differences).

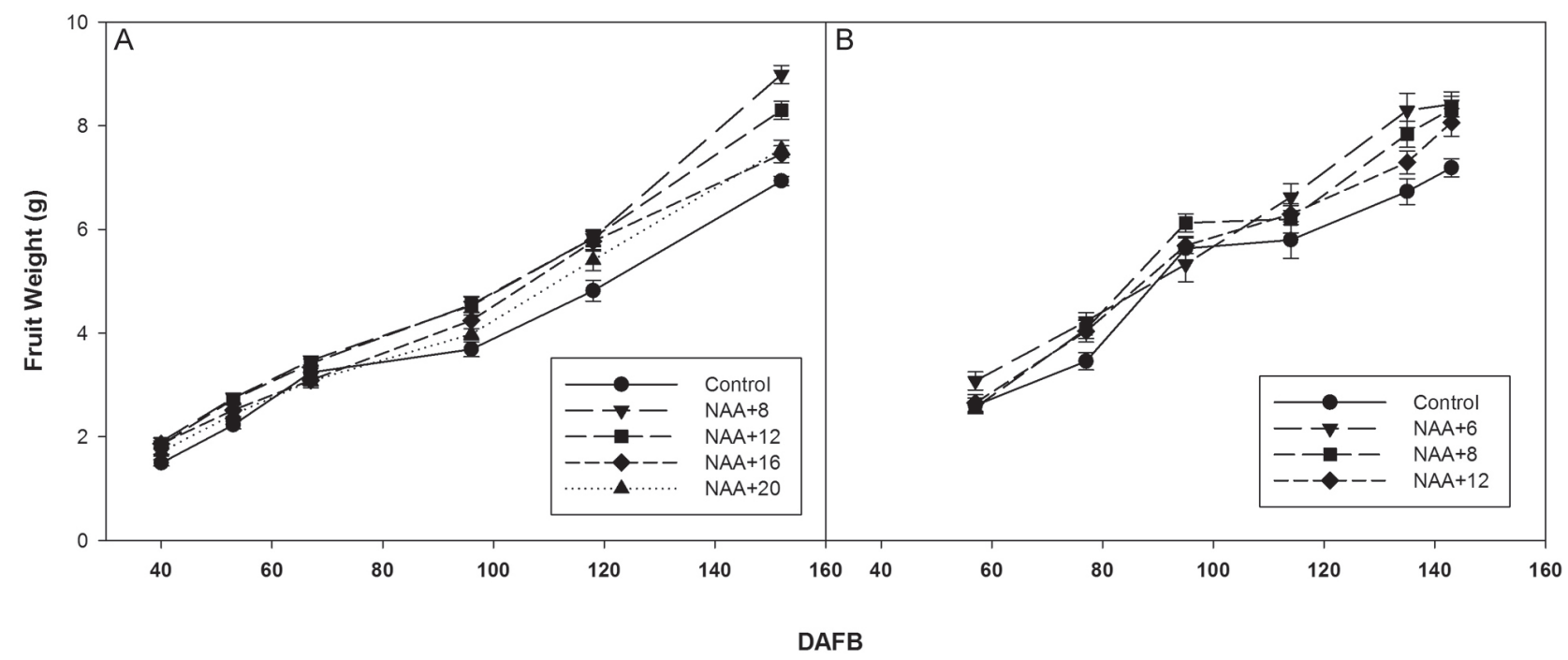

Figure 2 - Time-course of the table olive 'Nocellara del Belice' fruit fresh weight (g), after chemical thinning with naphthaleneacetic acid (NAA) (200 $\mathrm{mg} \mathrm{L}^{-1}$ ) at 6, 8, 12, 16 and 20 days after full bloom (DAFB). TCSA = Trunk cross-sectional area. Mean values \pm S.E.M. A: $2008 ;$ B: 2009. 
ger sink than the mesocarp, in accordance with previous studies (Rapoport et al., 2004), perhaps because endocarp development is linked to survival of the embryo. Proietti (2000) reported no clear correlation between heavy fruit load and photosynthesis efficiency, concluding that the depletion of carbohydrate reserves during an "on" year could negatively influence new leaves and thus flower bud formation. However, Bustan et al. (2011) recently showed that carbohydrate surplus or deficiency cannot be considered the cause of olive alternate bearing, thus, this phenomenon is probably regulated by hormonal factors (Stutte and Martin 1986; Ulger et al., 2004; Dag et al., 2009, 2010).

On the whole, carbohydrate resources fluctuate in response to sharp changes in source-sink relationships in the tree throughout the season playing a role in olive survival strategy (Bustan et al., 2011). Our results suggest that the carbohydrate reserve level may limit mesocarp growth, while pit weight seems to be influenced only by the current year's photo-assimilate availability. An olive endocarp growth period is much shorter as compared to the mesocarp growth period and occurs in a less stressful period of the season (Hammani et al., 2011).

Severe or complete removal of the fruits brings considerable vegetative growth, bloom and fruit yield in the following year (Dag et al., 2010), although it does not seem to intensely alter the carbohydrate reserves at the end of the olive reproductive cycle (Bustan et al., 2011). Rather than carbohydrate reserves, it is likely that the main factor responsible for the alternate bearing phenomenon is constituted by inhibitor signals produced by the developing embryos (Lavee, 2007).

In both the "on" and "off" years under observation, no differences among the treatments were found for these two parameters: trunk cross-sectional area and yield per tree (Table 1). Nevertheless, earliest thinning treatments reduced crop density in both years.

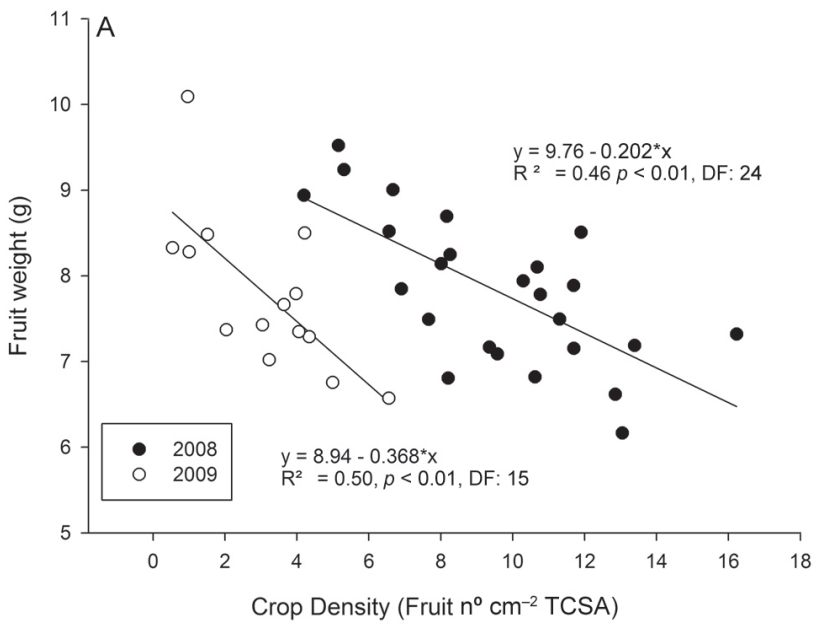

In the first year, both the fruit weight and the flesh to pit ratio, and in the second year, the fruit weight only were increased $(p<0.05)$ by the earliest application of NAA compared to the control. More detailed information about the commercial value of the production, as affected by the time of thinning, can be observed by the percent of fruit distribution in the size classes (Figure 4). NAA application timings, as a whole, led to fruit size improvement that reduced the fraction of small fruits not suited to canning (fruit diameter $\leq 18 \mathrm{~mm}$ ). On the other hand, considerable amounts of olives (> $80 \%$ ) were classified in the highest size class ("00") only with NAA at $\mathrm{FB}+8$ and at $\mathrm{FB}+12$ in 2008 and with $\mathrm{NAA}$ at $\mathrm{FB}+6$ and $\mathrm{FB}+8$ in 2009. On the basis of this trial, chemical thinning cannot overcome alternate bearing of the olive table 'Nocellara del Belice'. This observation suggests the existence of other factors, in addition to crop load, which can affect the regularity of cropping in olive, such as genetically determined factors, hormonal control, nutrient competition, starch content, sink-source relationships, inhibition exerted by the embryos, environmental conditions and the influence of cultural techniques (Lavee, 2007).

It is possible, with an early foliar application of the chemical thinner NAA, to control fruit size, and enhance fruit market quality without any reduction in yield for the main Italian table olive cultivar 'Nocellara del Belice'. An improvement of average fruit weight and percent fruit size distribution was obtained when NAA (concentration $200 \mathrm{mg} \mathrm{L}^{-1}$ ) was applied early, i.e. 6-12 DAFB. Later applications showed less thinning efficacy, perhaps due to the environmental conditions or physiological stage of fruit development. These findings confirm that timing is critical and that the number of days after full bloom in which NAA can be successfully used is somewhat limited as has already been documented (Barranco and Krueger, 1990). Nevertheless, the intrin-

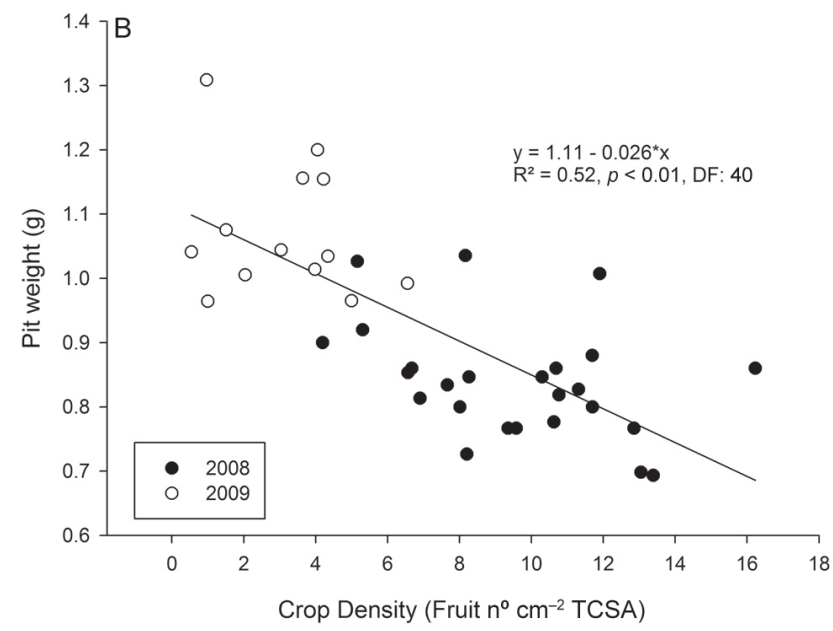

Figure 3 - Relationships between crop density and fruit fresh weight (A) and between crop density and pit weight (B), in table olive 'Nocellara del Belice' after chemical thinning with naphthaleneacetic acid (NAA) (200 $\left.\mathrm{mg} \mathrm{L}^{-1}\right)$. 


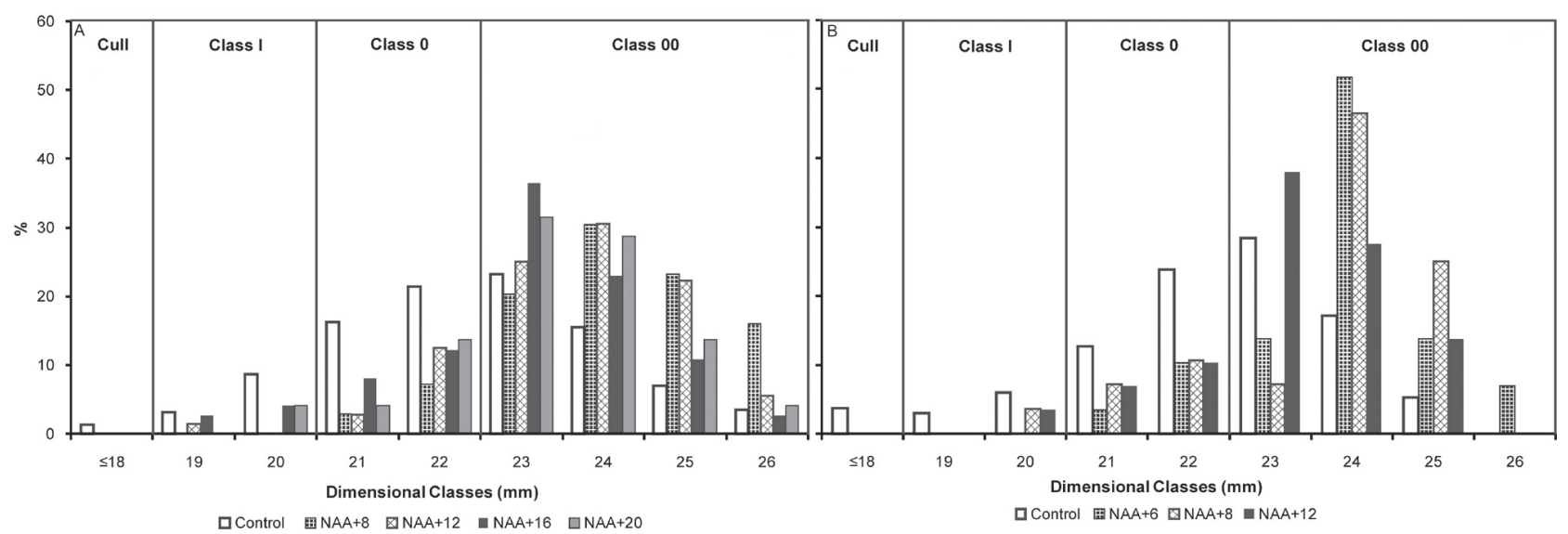

Figure 4 - Percent of fruit distribution in commercial dimensional classes of the table olive 'Nocellara del Belice' after chemical thinning with naphthaleneacetic acid (NAA) (200 $\mathrm{mg} \mathrm{L}^{-1}$ ) at 6, 8, 12, 16 and 20 days after full bloom (DAFB). A: 2008; B: 2009.

sic variability observed among the data and between the years, that may be related to environmentally affected factors (Krueger et al., 2002; Wertheim and Webster, 2005), suggests the need to combine calendar references (full bloom) with other methods (e.g. fruitlet size) in order to better define the timing of NAA application in the future.

In conclusion, NAA application can became a routine horticultural practice in table olive growing areas in Italy to regulate crop size, that will improve fruit quality and increase economic returns in the "on" year.

\section{Acknowledgements}

To Dr. Daniel Sargent, for reviewing our paper.

\section{References}

Baratta, B.; Caruso, T.; Inglese, P. 1992. Urea as a thining agent in olive: the influence of concentration and time of application. Journal of Horticultural Science 67: 219-224.

Barone, E.; Gullo, G.; Zappia, R.; Inglese, P. 1994. Effect of crop load on fruit ripening and olive oil (Olea europaea L.) quality. Journal of Horticultural Science 69: 67-73.

Barranco, D.; Krueger, W.H. 1990. Timing of NAA application in olive thinning. Acta Horticulturae 286: 167-169.

Bustan, A.; Avni, A.; Lavee, S.; Zipori, I.; Yeselson, Y.; Schaffer, A.A.; Riov, J.; Dag, A. 2011. Role of carbohydrate reserves in yield production of intensively cultivated oil olive (Olea europaea L.) trees. Tree Physiology 31: 519-530.

Dag, A.; Bustan, A.; Avni, A.; Lavee, S.; Riov, J. 2009. Fruit thinning using NAA shows potential for reducing biennial bearing of 'Barnea' and 'Picual' oil olive trees. Crop and Pasture Science 60: 1124-1130.

Dag, A.; Bustan, A.; Avni, A.; Tzipori, I.; Lavee, S.; Riov, J. 2010. Timing of fruit removal affects concurrent vegetative growth and subsequent return bloom and yield in olive (Olea europaea L.). Scientia Horticulturae 123: 469-472.
Fernandez-Escobar, R.; Benllloch, M.; Navarro, C.; Martin, G.C. 1992. The time of floral induction in the olive. Journal of the American Society for Horticultural Science 110: 303-309.

Gucci, R.; Lodolini, E.; Rapoport, H.F. 2007. Productivity of olive trees with different water status and crop load. The Journal of Horticultural Science and Biotechnology 82: 648-656.

Hammani, S.B.M.; Manrique, T.; Rapoport, H.F. 2011. Cultivarbased fruit size in olive depends on different tissue and cellular processes throughout growth. Scientia Horticulturae 130: 445451.

Hartmann, H.T. 1952. Spray thinning of olives with naphtaleneacetic acid. Proceedings of the American Society for Horticultural Science 59: 187-195.

Krueger, W.H.; Heat, Z.; Mulqueeney, B. 2002. Effect of spray solution concentration, active ingredient, additives and sequential treatments of Naphtalene Acetic Acid for chemical thinning of Manzanillo tavle olives (Olea europea). Acta Horticulturae 586: 267-271.

Lavee, S. 1989. Involvement of plant growth regulators and endogenous growth substances in the control of alternate bearing. Acta Horticulturae 239: 311-322.

Lavee, S. 2007. Biennial bearing in olive (Olea europaea). Annales: Series Historia Naturalis 17: 101-112.

Lavee, S.; Spiegel-Roy, P. 1967. The effect of time of application of two growth substances on the thinning of olive fruits. Journal of the American Society for Horticultural Science 91: 180-186.

Lavee, S.; Wodner, M. 1991. Factors affecting the nature of oil accumulation in fruit of olive (Olea europaea L.) cultivars. Journal of Horticultural Science and Biotechnology 66: 583591.

Lavee, S.; Wodner, M. 2004. The effect of yield, harvest time and fruit size on the oil content in fruit of irrigated olive trees (Olea europaea L.), cvs. Barnea and Manzanillo. Scientia Horticulturae 99: 267-277.

Lombard, P.B.; Callan, N.W.; Dennis, F.G.; Looney, N.E.; Martin, G.C. 1988. Towards a standardized nomenclature, procedures, values, and units in determining fruit and nut tree yield performance. Horticultural Science 23: 813-817. 
Maranto, J.; Krueger, W. 1994. Olive fruit thinning. p. 87-89. In: Ferguson, L.; Sibbett, G.S.; Martin, G.C., eds. Olive production manual. University of California, Oakland, CA, USA.

Marra, F.P.; Caruso, T.; Costa, F.; Vaio, C.; Mafrica, R.; Marchese, A. 2013. Genetic relationships, structure and parentage simulation among the olive tree (Olea europaea L. subsp. europaea) cultivated in Southern Italy revealed by SSR markers. Tree Genetics and Genomes. DOI: http://dx.doi.org/10.1007/ s11295-013-0609-9.

Martin, G.C.; Lavee, S.; Sibbett, G.S.; Nishijima, C.; Carlson, S.P. 1980. A new approach to thinning olives. California Agriculture 34: 7-8.

Martin, G.C.; Connell, J.H.; Freeman, M.W.; Krueger, W.H.; Sibbett, G.S. 1994. Efficacy of foliar application of two naphthalenacetic acid salts for olive fruit thinning. Acta Horticulturae 356: 302-305.

Proietti, P. 2000. Effect of fruiting on leaf gas exchange in olive (Olea europaea L.). Photosynthetica 38: 397-402.

Proietti, P.; Nasini, L.; Famiani, F. 2006. Effect of different leafto-fruit ratios on photosynthesis and fruit growth in olive (Olea europaea L.). Photosynthetica 44: 275-285.

Rallo, L.; Barranco, D. 1986. Influence of the time of application on the response of olive to chemical thinning. Acta Horticulturae 179: 709-710.
Rapoport, H.F.; Costagli, G.; Gucci, R. 2004. The effect of water deficit during early fruit development on olive fruit morphogenesis. Journal of the American Society for Horticultural Science 129: 121-127.

Stutte, G.; Martin, G.C. 1986. Effect of killing the seed on return bloom olive. Scientia Horticulturae 149: 131-134.

Troncoso, A.; Prieto, J.; Linan, J. 1978. Aclareo quimico de frutos en el olivar Manzanillo de Sevilla (Chemical fruit thinning in orchard of Manzanillo de Sevilla). Anales de Edafologia y Agrobiologia 37: 882-893.

Ulger, S.; Sonmez, S.; Karkacier, M.; Ertoy, N.; Akdesir, O.; Aksu, M. 2004. Determination of endogenous hormones, sugars and mineral nutrition levels during the induction, initiation and differentiation stage and their effects on flower formation in olive. Plant Growth Regulation 42: 89-95.

Wertheim, S.J.; Webster, A.B. 2005. Manipulation of growth and development by plant bioregulators. p. 267-294. In: Tromp, J.; Webster, A.D.; Wertheim, S.J., eds. Fundamentals of temperate zone tree fruit production. Backhuys, Leiden, Netherlands.

Williams, K.M.; Fallahi E. 1999. The effects of exogenous bioregulators and environment on regular cropping of apple. HortTechnology 9: 323-327. 